\title{
PREDIKSI PERMEABILITAS MENGGUNAKAN METODE PORE GEOMETRY STRUCTURE (PGS) PADA DAERAH CEKUNGAN JAWA BARAT UTARA
}

\author{
Ayu Yuliani ${ }^{1}$, Ade Yogi $^{2}$, Ordas Dewanto ${ }^{3}$, Karyanto ${ }^{4}$ \\ 1,3,4 Jurusan Teknik Geofisika, Fakultas Teknik Universitas Lampung \\ ${ }^{2}$ Pusat Survei Geologi, Badan Geologi, Kementrian "ESDM"
}

Corresponding author: ayuyuliani82@gmail.com

Manuscript received : Jan 19 $1^{\text {th }}, 2020$, revised : Jan $22^{\text {nd }}, 2020$;

Approved: Jan 28, 2020; Available online : Mar 20 th 2020

\begin{abstract}
Abstrak - Penentuan properti batuan reservoir sangat penting dilakukan agar memahami reservoir yang lebih baik. Salah satu properti batuan tersebut adalah permeabilitas. Permeabilitas merupakan kemampuan suatu batuan agar dapat melewatkan fluida. Pada penelitian ini, perhitungan permeabilitas dilakukan dengan menggunakan metode Schlumberger, Timur, Morris Biggs Oil, Morris Biggs Gas,dan PGS (Pore Geometry Structure) berdasarkan data core, log, dan CT Scan. Pada metode Schlumberger, Timur, Morris Biggs Oil, dan Morris Biggs Gas, perhitungan permeabilitas dilakukan dengan analisis petrofisika yang bertujuan untuk mengevaluasi formasi zona target penelitian seperti perhitungan sebaran kandungan serpih (volume shale), porositas efektif, saturasi air, dan permeabilitas. Determinasi nilai porositas dari CT Scan, dilakukan pada 2 data core sebanyak 20 tube, setiap tube diplot sebanyak 15 titik. Outputnya adalah nilai Porositas $C T$ yang akan digunakan untuk sebaran prediksi nilai permeabilitas PGS. Pada metode PGS, dilakukan rock typing berdasarkan deskripsi geologi, kemudian perhitungan prediksi permeabilitas. Menggunakan dua metode tersebut, dapat dilakukan perhitungan permeabilitas pada daerah penelitian. Hasil perhitungan permeabilitas PGS menunjukkan korelasi yang baik antara hasil perhitungan Permeabilitas PGS dengan data core. Terlihat dari data hasil perhitungan permeabilitas PGS mendekati gradien bernilai satu dengan $R^{2}$ sebesar 0.906 . Sedangkan metode lain memiliki $R^{2}$ sebesar 0.845 .
\end{abstract}

\begin{abstract}
One of the rock properties that must be determined is permeability. Permeability is a rock's ability to pass fluid. The calculation of permeability was done using log and PGS (Pore Geometry Structure) methods based on core, logs, and CT-Scans data. In log method, the permeability calculation is done by petrophysical analysis which aims to evaluate the research zone formation as calculation of the distribution of shale content, effective porosity, water saturation and permeability. The determination of porosity values from CT-Scan, performed on 2 data cores of 20 tubes, each tube was plotted as many as 15 points. The output is the CTPorosity value that will be used for the distribution of predictions of PGS permeability. In the PGS method, rock typing is based on geological descriptions, then calculation of permeability predictions. Using these two methods, permeability can be calculated in the study area. The results of PGS permeability calculations show a good correlation between the results of the calculation of PGS permeability and core data. It can be seen from the results of PGS permeability that the gradient is one with $R^{2}$ of 0.906 . Whereas another method has an $R^{2}$ of 0.845 .
\end{abstract}

Keywords: Calculation, CT Scan, Permeability, Pore Geometry Structure (PGS), Petrophysical

How to cite this article:

Yuliani, A., Yogi, A., Dewanto, O., dan Karyanto, 2020, Prediksi Permeabilitas Menggunakan Metode Pore Geometry Structure (PGS) Pada Daerah Cekungan Jawa Barat Utara, Jurnal Geofisika Eksplorasi, 6 (1) p.3-17. doi: 10.23960/jge.v6i1.57

\section{PENDAHULUAN}

Penentuan properti batuan reservoir sangat penting dilakukan agar dapat memahami reservoir yang lebih baik.
Beberapa properti batuan tersebut adalah porositas dan permeabilitas. Permeabilitas berperan penting dalam kehidupan awal lapangan minyak dan dalam melakukan karakterisasi serta deskripsi reservoir 
(Reservoir Characterization and Description) untuk tujuan pengelolaan reservoir, karena produksi sangat bergantung pada permeabilitas.

Penentuan nilai permeabilitas dapat dilakukan dengan menggunakan metode Schlumberger, Timur, Morris Biggs Oil, dan Morris Biggs Gas dan pore geometry structure (PGS). Pada penentuan nilai permeabilitas dengan metode log, menggunakan beberapa data log berupa: log gamma ray, resistivitas, dan neutron porosity hydrogen index (NPHI) dan densitas batuan $(R H O B)$. Berdasarkan data $\log$ tersebut, dapat dilakukan analisis petrofisika berupa penentuan porositas, saturasi air, permeabilitas, dan kandungan serpih.

Jumlah kandungan serpih di Indonesia sangat banyak, sehingga diharapkan dalam beberapa tahun kedepan akan tersedia banyak sumber minyak dan gas. Membutuhkan waktu yang lama untuk menunggu proses perubahan material serpih menjadi minyak dan gas (Dewanto, dkk., 2017).

Penelitian sebelumnya dengan mengangkat tema tentang determinasi pengelompokkan batuan dan prediksi permeabilitas yang telah dilakukan oleh Permadi dan Wibowo (2013), bahwa aspek geologi dan teknik reservoir sangat dipertimbangkan pada penelitian ini. Dimana, diketahui bahwa geometri dan struktur pori dapat diaplikasikan dalam pegelompokkan batuan (rock typing) serta menjadi dasar dalam perhitungan prediksi permeabilitas. Hasil penelitian dengan metode ini menunjukkan bahwa terdapat kaitan erat antara kemiripan arsitektur pori dengan geologi (lithofacies dan diagenesa) yang serupa.

Menurut Yogi (2018), metode yang digunakan dalam penentuan tipe batuan akan sangat mempengaruhi hasil perhitungan permeabilitas. Permeabilitas merupakan hasil dari proses geologi sehingga setiap tipe batuan dalam suatu reservoir memiliki karakter permeabilitasporositas yang unik. Oleh karena itu, penentuan tipe batuan harus dilakukan menggunakan metode yang tepat, agar nilai hasil prediksi permeabilitas akan mendekati nilai permeabilitas nyatanya. Metode yang dapat digunakan untuk memprediksi nilai permeabilitas adalah pendekatan Pore Geometry Structure (PGS). Metode Pore Geometry Structure (PGS) sangat bagus digunakan untuk pengelompokkan tipe batuan. Karena pada metode ini melakukan sebaran geometri dan struktur pori, dimana geometri dan struktur pori (arsitektur pori) sangat berpengaruh dalam porositas dan akan berkaitan dengan hasil prediksi permeabilitas. Selain itu, pada metode ini, persamaan diperoleh dari korelasi hubungan porositas, permeabilitas, dan irreducible water saturation.

Adapun tujuan penelitian ini adalah Menentukan dan menganalisis nilai permeabilitas menggunakan metode Pore Geometry Structure (PGS) berdasarkan data CT-Scan dan dibandingkan dengan metode lain.

\section{TINJAUAN PUSTAKA}

Cekungan Jawa Barat Utara terdiri dari dua area yaitu darat (onshore) dan laut (offshore) di Utara dan di Selatan pulau Jawa. Semua daerah didominasi oleh patahan ekstensional (extensional faulting) dengan struktur kompresional yang sangat sedikit. Cekungan didominasi oleh rift yang berkaitan dengan patahan (fault) yang membentuk beberapa struktur deposenter(half graben), deposenter utamanya yaitu Sub-Cekungan Arjuna dan Sub-Cekungan Jatibarang. Deposenter lainnya yaitu Sub-Cekungan Ciputat dan Sub-Cekungan Pasirputih. Deposenterdeposenter tersebut didominasi oleh sekuen tersier dengan ketebalan melebihi $5500 \mathrm{~m}$. Struktur yang penting pada cekungan tersebut yaitu terdiri dari bermacam-macam area tinggian yang berhubungan dengan antiklin yang terpatahkan dan blok tinggian (horst 
block), lipatan pada bagian yang turun pada patahan utama, keystone folding dan mengena pada tinggian batuan dasar. Struktur kompresional hanya terjadi pada awal pembentukan rift pertama yang berarah relatif barat laut-tenggara pada periode Paleogen (Darman dan Sidi, 2000). Batuan dasar pada cekungan ini adalah batuan beku andesitik dan basaltik yang berumur Kapur Tengah sampai Kapur Atas dan batuan metamorf yang berumur Pra Tersier (Sinclair, et.al, 1995).

Well Logging merupakan sutau metode yang digunakan untuk mengukur parameter-parameter fisika dalam borhole yang beragam terhadap kedalaman sumur. Analisis petrofisika dapat diaplikasikan untuk mengetahui dan mengevaluasi formasi berupa porositas, saturasi air, dan permeabilitas yang akan digunakan untuk menentukan tahap eksplorasi dan produksi selanjutnya (Irawan dan Utama, 2009).

Permeabilitas ditandai dengan $k$ dinyatakan dalam $m D$ (milidarcies), merupakan kemampuan mengalir dari cairan formasi. Permeabilitas sangat bergantung pada ukuran butir dari batuan (Harsono, 1994). Pada data Log, besarnya permeabilitas suatu batuan tergantung pada porositas dan saturasi air dan dapat dihitung dengan menggunakan Persamaan 1 berikut ini:

$$
k=a \frac{\phi^{b}}{S w^{c}}
$$

Dimana $k$ merupakan permeabilitas (milidarcies); $\Phi$ merupakan porositas efektif (fraksi); $S w$ merupakan saturasi air (fraksi); $a$ merupakan konstanta (Schlumberger $=10000$, Morris Biggs Gas $=6241$, Morris Biggs Oil = 62500, Timur $=8581) ; b$ merupakan konstanta (Schlumberger $=4.5$, Morris Biggs Gas $=$ 6, Morris Biggs Oil = 6, Timur = 4.4); c merupakan konstanta (Schlumberger $=2$, Morris Biggs Gas = 2, Morris Biggs Oil= 2, Timur = 2).

Pada metode pore geometry structure (PGS), terdapat 2 tahapan yaitu: identifikasi flow unit dan prediksi permeabilitas. Menurut Yogi (2018), Integrasi data dari routine core, special core, dan deskripsi geologi dapat digunakan untuk pengelompokkan tipe batuan (rock typing). Pengelompokkan tipe batuan berdasarkan lithofacies dan porositas sekunder dilakukan berdasarkan korelasi hubungan antara lithofacies, geometri pori dan struktur pori (arsitektur pori). Geometri pori atau dikenal sebagai radius hidrolik rata-rata dilambangkan dengan $\left(\frac{k}{\varnothing}\right)^{0.5}$, sedangkan struktur pori yang menjelaskan semua fitur struktur internal dari pori-pori dilambangkan dengan $\frac{k}{\emptyset^{3}}$. Hubungan antara geometri pori dan struktur pori ditampilkan pada Persamaan 2 berikut ini:

$$
\left(\frac{k}{\varnothing}\right)^{0.5}=\varnothing x\left(\frac{k}{\emptyset^{3}}\right)^{0.5}
$$

atau,

$$
\left(\frac{k}{\varnothing}\right)^{0.5}=\frac{V_{p}}{V_{b}} x\left(\frac{k}{\varnothing^{3}}\right)^{0.5}
$$

Plotting data $\left(\frac{k}{\varnothing}\right)^{0.5}$ sebagai variabel dependen terhadap $\frac{k}{\emptyset^{3}}$ sebagai variabel independen pada grafik log-log akan menghasilkan garis lurus dengan kemiringan positif 0.5 dan $V p / V b=1$. Dengan memperlakukan media berpori sebagai tabung kapiler halus yang berlikuliku dan memiliki tebal dinding yang sangat kecil, dapat diturunkan sebagai persamaan Kozeny. Selain itu, istilah $\left(\frac{k}{\varnothing}\right)^{0.5}$ dalam persamaan di atas menyiratkan bahwa medium diperlakukan sebagai tabung kapiler halus tunggal yang memiliki $\varnothing=1$. Kondisi ini akan menyebabkan fluida mengalir dengan efisiensi aliran 1, artinya tidak terjadi penundaan aliran fluida pada titik manapun di dalam medium. Oleh karena itu, Persamaan 2 dapat mewakili model ideal dari media berpori memiliki geometri dan struktur pori yang sangat sederhana. 
Ketika berhadapan dengan batuan berpori nyata, kehadiran pori mikro, meso, dan makro, kontraksi pori, perbedaan pori, dan kekasaran dinding pori akan membuat aliran fluida jauh dari situasi yang ideal (Gardner, 1958). Kecepatan fluida yang mengalir dapat beragam secara signifikan dari satu lokasi pori ke stagnasi aliran lain dan bahkan terjadi di dead end apabila memungkinkan pada kondisi nyata dan kompleks. Dengan kata lain, volume fluida yang mengalir per satuan waktu dari satu posisi ke posisi lainnya akan berbeda. Oleh karena itu, diharapkan efisiensi aliran akan lebih kecil dari 1. Berikut ini merupakan persamaan tipe batuan untuk batuan berpori nyata ditunjukkan pada Persamaan 4:

$$
\left(\frac{k}{\varnothing}\right)^{0.5}=a\left(\frac{k}{\emptyset^{3}}\right)^{b}
$$

dimana konstanta a merupakan efisiensi aliran dan eksponen $b$ merupakan dapat mewakili kompleksitas pori (Permadi dan Wibowo, 2013).

Selain porositas, irreducible water saturation (Swirr) juga akan mempengaruhi hasil perhitungan permeabilitas. Dimana permeabilitas akan berbanding terbalik dengan irreducible water saturation (Swirr) dan berbanding lurus dengan porositas. Berdasarkan hubungan ketiga parameter tersebut, dapat dilakukan penentuan permeabilitas dengan mendapatkan persamaan antara permeabilitas dan saturasi air kemudian disubtitusikan pada setiap persamaan tipe batuan. Berikut ini merupakan bentuk umum persamaan antara permeabilitas, porositas, dan irreducible water saturation (Yogi, 2018):

$$
\text { Swirr }=M k^{-n}
$$

Subsitusikan Persamaan 5 ke $\sqrt{\frac{k}{\varnothing}}$ menghasilkan:

$$
\sqrt{\frac{k}{\varnothing}}=\left(\frac{M}{S w}\right)^{\frac{0.5}{n}}
$$

Subsitusikan Persamaan 4 ke Persamaan 6 akan menjadi:

$$
\left(\frac{M}{S w}\right)^{\frac{0.5}{n}}=a\left(\frac{k}{\emptyset^{3}}\right)^{b}
$$

$$
k=\left(\frac{M^{\frac{0.5}{n}}}{a}\right)^{\frac{1}{b}} x\left(\frac{\phi^{3-\frac{0.5}{b}}}{S w^{\frac{0.5}{n b}}}\right)
$$

Persamaan akhir hubungan antara porositas, permeabilitas, dan irreducible water saturation yang akan digunakan dalam perhitungan permeabilitas sebagai permeabilitas PGS ditunjukkan pada Persamaan 9 berikut ini:

$$
k=c\left(\frac{\phi^{A}}{S w^{B}}\right)
$$

dengan,

$$
\begin{aligned}
& A=3-\frac{0.5}{b} \\
& B=\frac{0.5}{n b} \\
& c=\left(\frac{M^{\frac{0.5}{n}}}{a}\right)^{\frac{1}{b}}
\end{aligned}
$$

\section{METODE PENELITIAN}

Adapun tahap pengolahan data pada penelitian ini secara garis besar adalah sebagai berikut: 1) perhitungan nilai permeabilitas dari data $\log ; 2$ ) penentuan tipe batuan berdasarkan deskripsi geologi; 3) penentuan final persamaan permeabilitas dengan pendekatan Pore Geometry Structure (PGS); 4) melakukan sebaran PGS dari data Porositas CT; dan 5) menganalisis hasil perhitungan prmeabilitas dari data log, core, dan metode PGS.

Data yang digunakan pada penelitian ini adalah: sampel batuan inti sumur AY-7 sebanyak 2 core memiliki 54 total plugs. Core 1 memiliki 25 plugs pada kedalaman $1776.00 \mathrm{~m}$ - $1785.80 \mathrm{~m}$ dan Core 2 memiliki 29 plugs pada kedalaman 1929.18 m - 1939.08 m; Data routine core yang digunakan adalah Porositas $(\varnothing$ dalam $\%$ ), dan permeabilitas ( $\mathrm{k}$ dalam $\mathrm{mD}$ ). Sedangkan data SCAL (Special Core Analysis) yang digunakan adalah Swirr (irreducible water saturation); Data $C T$ Scan yang diperoleh dari plotting $C T$ Number sebanyak 15 titik, memiliki total 
titik plot sebanyak 286 titik; Data log dalam format .LAS yang terdiri dari log gamma ray, caliper, spontaneous potential, resistivitas (LLD, LLS dan MSFL), neutron porosity hydrogen index (NPHI), dan densitas batuan (RHOB).

\section{HASIL DAN PEMBAHASAN}

Dalam menentukan dan memprediksi nilai permeabilitas pada sumur AY-7, perlu dilakukan beberapa proses pengolahan dan perhitungan data.

\subsection{Pengolahan Data Log dan Analisis Petrofisika}

Interpretasi sumur dilakukan pada sumur AY-7 dengan kedalaman 1776.00 $1785.50 \mathrm{~m}$ memiliki ketebalan sebesar 9,5 $\mathrm{m}$ (Zona 1) dan 1929.18 - $1939.18 \mathrm{~m}$ memiliki ketebalan sebesar $10 \mathrm{~m}$ (Zona 2).

\section{A. Volume Shale}

Parameter volume shale (Vsh) yang digunakan untuk perhitungan pada Sumur AY-7 adalah dengan log gamma ray, dimana nilai sand base line terletak pada nilai GRmin dan nilai shale base line terletak pada GRmaks berturut-turut adalah 149.940 gAPI dan 11.189 gAPI. Berdasarkan perhitungan volume shale ( Vsh) yang telah dilakukan, diperoleh hasil perhitungan $V s h$ pada Zona 1 adalah 5.43 $63.55 \%$ sedangkan pada Zona 2 adalah $1.60-14.51 \%$.

\section{B. Porositas}

Porositas dihitung dengan melibatkan parameter $V s h$ yang telah dihitung sebelumnya dan log NPHI. Hasil Perhitungan porositas total (PHIT) dan efektif (PHIE) pada Zona 1 dan 2 sumur AY-7: untuk Zona 1, PHIT dan PHIE berturut-turut adalah $11.318 \%$ dan $4.995 \%$. Sedangkan untuk Zona 2, PHIT dan PHIE berturut-turut adalah $5.08 \%$ dan $3.88 \%$. Hasil perhitungan tersebut menunjukkan bahwa nilai PHIT lebih besar dibandingkan dengan nilai $P H I E$, hal ini mengindikasikan bahwa porositas pada reservoir tidak saling berhubungan.

C. Resistivitas Air

Resistivitas air merupakan nilai ketahanan jenis air terhadap arus listrik. Penentuan nilai resistivitas air dapat menggunakan metode pickett plot dengan melakukan kurva silang antara PHIE (porositas efektif) dengan $R t$ (resistivitas formasi; pembacaan dari kurva $\log$ LLD), kemudian menarik garis pada kumpulan titik-titik terbanyak sehingga diperoleh nilai $R w$ nya. Gambar $\mathbf{1}$ berikut ini merupakan hasil crossplot LLD/PHIE sumur AY-7. Diperoleh nilai $R w$ hasil dari crossplot LLD/PHIE sebesar 0.373 ohm.m, dengan nilai $\mathrm{a}, \mathrm{m}$, dan $\mathrm{n}$ berturut-turut adalah 1, 1.24, dan 1.9.

\section{Saturasi Air}

Berdasarkan tinjauan geologi regional daerah penelitian, litologi penyusun pada formasi target penelitian adalah perselingan antara batugamping dan serpih serta perselingan batupasir dan serpih. Hal ini menunjukkan bahwa pada formasi target penelitian tidak dapat dikatakan sebagai zona bersih, karena adanya perselingan serpih. Serta hasil perhitungan volume pengotor (volume shale) yang telah dilakukan sebelumnya menunjukkan hasil yang cukup besar yaitu 1-28\%. Oleh karena itu, perhitungan saturasi air dilakukan menggunakan Persamaan Simandoux. Dimana parameter-parameter yang digunakan adalah porositas efektif $\left(\phi_{\text {eff }}\right)$, resistivitas air formasi $(R w)$, resistivitas formasi (Rt) pembacaan dari kurva $\log L L D$, resistivitas shale (Rsh), dan volume shale (Vsh).

Nilai saturasi air yang besar tidak bagus dalam suatu reservoir, karena jika saturasi air bernilai besar akan menunjukkan bahwa zona tersebut memiliki kandungan air yang banyak. Hal ini akan mempengaruhi keekonomisan suatu reservoir tersebut. Pada penelitian ini, diperoleh nilai saturasi air Zona 1 lebih 
kecil dibandingkan Zona 2 yang dominan bernilai $100 \%$.

\section{E. Permeabilitas}

Permeabilitas yang dihitung tidak hanya menggunakan metode PGS, tetapi menggunakan 4 permeabilitas lainnya (permeabilitas log) yaitu Schlumberger, Timur, Morris Biggs Oil, dan Morris Biggs Gas. Dari keempat permeabilitas tersebut dan divalidasi dengan data core, diperoleh hasil yang akurat untuk Zona 1 adalah permeabilitas Morris Biggs Gas dan Zona 2 adalah permeabilitas Timur.

Menurut Koesoemadinata (1980), kualitas permeabilitas dalam suatu reservoir terbagi menjadi 4 kategori yaitu: kurang dari $5 \mathrm{mD}$ dikatakan ketat (tight); 5 - 10 mD dikatakan cukup (fair); 10 - 100 $\mathrm{mD}$ dikatakan baik (good), $100-1000 \mathrm{mD}$ dikatakan sangat baik (very good). Berdasarkan kategori tersebut, hasil perhitungan permeabilitas pada Zona 1 dan 2 Sumur AY-7 dapat dikategorikan ke dalam permeabilitas tight (ketat) dimana nilainya kurang dari $5 \mathrm{mD}$. Tampilan hasil akhir perhitungan permeabilitas log dapat dilihat pada Gambar 2 dan 3.

\subsection{Determinasi nilai Porositas dari $C T$ Scan}

Menurut Listiyowati (2018), nilai $C T$ merepresentasikan kesamaan dengan tingkat keabuan. Citra hasil rekonstruksi dengan kode warna dimana warna yang lebih gelap dapat diindikasikan sebagai area dengan densitas yang rendah, dan mengindikasikan pori-pori yang terisi oleh udara. Tingkat keabuan dapat menunjukkan nilai $C T$, untuk tingkat keabuan yang gelap diidentifikasi sebagai pori dan mempunyai nilai $C T$ yang rendah. Citra gambar berwarna hitam menunjukkan pori (udara), warna abu-abu menunjukkan kepadatan matriks padat yang rendah, dan warna putih terang menunjukkan kepadatan matriks padat yang lebih tinggi (Demir and Demiral, 2001).
Porositas $C T$ diperoleh dari plotting nilai CTnumber menggunakan software VoxcelCalc. Plus v8.23a sebanyak 15 titik tiap satu data hasil scanning (sepanjang 1 $\mathrm{m})$. Tujuan dari plotting ini adalah untuk mendapatkan nilai porositas hasil dari $C T$, kemudian dikorelasikan dengan nilai porositas core lalu analisis keakuratan nilainya. Data porositas $C T$ ini akan digunakan untuk menentukan sebaran PGS pada tiap titik plotting dalam prediksi permeabilitas dengan pendekatan Pore Geometry Structure (PGS).

Hasil perhitungan porositas $C T$ tidak berbeda jauh atau mendekati nilai porositas core, dapat dikatakan selisihnya masih dalam batas wajar. Namun, masih ada beberapa titik yang sedikit jauh dari nilai porositas core. Selisih ini disebabkan karena pada saat plotting zona tiap titik tidak sama ukurannya, sehingga jika melingkari zona terlalu besar porositas akan terhitung besar juga. Selain itu, pada saat melingkari zona mengenai tutup tube bagian top depth. Tutup depth ini berbahan logam, apabila pada saat plot zona mengenai maka nilai CTnumber-nya besar sehingga porositas yang terhitung juga akan besar.

\subsection{Prediksi Permeabilitas dengan Pendekatan Metode Pore Geometry Structure (PGS)}

Dalam penentuan permeabilitas, korelasi empiris yang diperoleh sama dengan persamaan yang diturunkan secara teoritis untuk model tabung kapiler kecuali kekuatan diameter hidrolik pori yang bernilai kurang dari 2. Berdasarkan hal tersebut, dapat diketahui bahwa model kapiler dapat digunakan sebagai pendekatan untuk mengkarakterisasi geometri pori dan struktur pori karena diameter hidraulik efektif (geometri pori) yang diturunkan dapat mencerminkan struktur sistem pori-pori. Model ini juga dapat digunakan untuk mengidentifikasi tipe batuan (Permadi dan Susilo, 2009). 
Dalam penelitian ini, pengelompokkan batuan dilakukan dengan menggunakan metode PGS dan didasarkan atas penggunaan PGS rock type curve. Rock type curve diperoleh dari korelasi antara deskripsi geologi, geometri pori dan struktur pori dalam grafik log-log. Hal ini akan menunjukkan karakter batuan disetiap rock type, dimana semakin besar nilai geometri dan struktur pori maka kualitas suatu batuan tersebut akan semakin baik. Gambar 4 merupakan kurva hasil plot antara geometri dan struktur pori.

Gambar tersebut menunjukkan hasil klasifikasi berdasarkan tekstur batuan atau ukuran butir. Dapat dilihat pada gambar tersebut, klasifikasi ukuran butir menunjukkan persebaran yang kompleks. Terdapat 2 pembagian utama pengelompokkan batuan, yaitu: kelompok pertama yang berada didalam lingkaran berwarna hijau, menunjukkan batuan tersebut memiliki kesamaan karakteristik yaitu batugamping berserpih (Limestone Shally). Kelompok 2 yang berada didalam lingkaran berwarna biru, menunjukkan kesamaan karakteristik yaitu batugamping berserpih dengan stilolit (Limestone Shally with Stylolite). Terlihat pada setiap lingkaran terdapat beberapa titik yang berada diluar daerahnya atau bukan daerahnya (menyimpang dari kelompoknya), untuk data yang berada dilingkaran hijau disebabkan karena titik tersebut tidak terdapat stylolite. Sedangkan data yang berada dilingkaran biru disebabkan karena pada titik tersebut terdapat stylolite dan berfracture.

Selanjutnya, penentuan final tipe batuan dalam kurva PGS. Dari 2 kelompok tipe batuan tersebut, dikelompokkan lagi dengan karakteristik deskripsi geologinya seperti nama batuan, ukuran butir, dan jenis mineral. Hasil penentuan rock type pada kurva PGS ditampilkan pada Gambar 5.

Berdasarkan hasil plot dari geometri dan struktur pori pada Gambar 5, diperoleh final tipe batuan pada kurva PGS dengan 4 kelompok. Tipe Batuan (RT) 1, didominasi oleh Batuan Gamping Serpih dengan stylolite, berwarna dari abu-abu gelap-terang dan ukuran butir dari sangat halus sampai halus. Tipe Batuan (RT) 2, didominasi oleh Batuan Gamping Serpih dengan stylolite, berwarna abu-abu gelapterang, ukuran butir halus-sangat halus, dan mengandung karbonatan. Tipe Batuan (RT) 3, didominasi oleh Batuan Gamping Serpih dengan stylolite, berwarna abu-abu gelap-terang, ukuran butir halus-sangat halus, dan mengandung mineral kuarsa. Tipe Batuan (RT) 4, didominasi oleh Batuan Gamping Serpih, berwarna abu-abu gelap-terang, dan ukuran butir halus-sangat halus. Tipe batuan 1 memiliki nilai eksponen yang tertinggi yaitu 0.4917 dan menurun sampai nilai terendah yaitu 0.2256 untuk Tipe batuan 4. Nilai eksponen ini merepresentasikan faktor bentuk dan distribusi ukuran pori, sedangkan konstanta tidak merepresentasikan apapun. Tabel $\mathbf{1}$ merupakan hasil klasifikasi rock type PGS dan deskripsi geologinya.

Untuk menentukan persamaan antara permeabilitas, porositas, dan irreducible water saturation perlu dilakukan subsitusi persamaan antara permeabilitas dan irreducible water saturation (Swirr) pada setiap persamaan tipe batuan. Dengan melakukan Plot nilai Swirr terhadap $k$ pada kurva semilog, akan diperoleh nilai $M$ dan $n$ (konstanta dan eksponen).

Berdasarkan regresi semilog pada kurva tersebut diperoleh nilai $M$ (konstanta) sebesar 0.594 dan $n$ (eksponen) sebesar 0.145. Sebelumnya, dari hasil plot ukuran butiran pada kurva PGS menghasilkan konstanta dan eksponen ( $a$ dan $b$ ) untuk tiap tipe batuan. Nilai $M, n, a$, dan $b$ ini akan digunakan untuk menghitung nilai $A, B$, dan $c$ menggunakan Persamaan 10, 11, dan 12. Nilai $A, B$, dan $c$ ini akan digunakan sebagai konstanta dan eksponen pada persamaan permeabilitas PGS. Tabel 2 merupakan hasil perhitungan nilai $A, B$, dan $c$ untuk setiap tipe batuan. 
Selanjutnya, untuk mendapatkan persamaan final prediksi permeabilitas dapat menggunakan Persamaan 9. Persamaan permeabilitas yang merupakan fungsi dari porositas dan saturasi air ditunjukkan pada Tabel 3.

Untuk mendapatkan persamaan prediksi permeabilitas yang dapat diaplikasikan pada sumuran, maka dapat dilakukan sebaran PGS menggunakan software Interactive Petrophysic berdasarkan data Porositas $C T$ yang telah ditentukan sebelumnya. Menggunakan prinsip fuzzy logic, dengan data inputan berupa data porositas $C T$ dan 4 kelompok Rock Type, yaitu PGS-1 (RT-1) sampai PGS-4 (RT-4). Dalam prinsip fuzzy logic, ada bagian yang perlu diperhatikan yaitu number of bin. Pada penelitian ini, penulis mencoba number of bin 5, 10, dan 15. Hasil yang mendekati sebenarnya adalah pada bin 5. Hasil sebaran PGS ini kemudian disimpan dalam format ASCII, untuk digunakan dalam perhitungan permeabilitas PGS tiap data depth $C T$. Hasil sebaran PGS untuk Zona 1 dan 2 sumur AY-7 ditampilkan pada Gambar 5.

Sebaran PGS yang telah dilakukan, disesuaikan dengan persamaan permeabilitas PGS tiap rock type. Perhitungan permeabilitas PGS dapat dilakukan dengan menggunakan Persamaan final prediksi permeabilitas PGS. Hasil perhitungan permeabilitas PGS data Zona 1 dan 2 sumur AY-7 ditampilkan pada Tabel 4. Berdasarkan Tabel 4, hasil perhitungan permeabilitas PGS tidak berbeda jauh atau mendekati nilai permeabilitas core. Selisihnya masih dalam batas wajar. Namun, masih ada beberapa titik yang sedikit jauh dari nilai permeabilitas core.

Setelah diperoleh hasil perhitungan permeabilitas Core, Log, dan PGS, selanjutnya adalah membandingkan hasil perhitungan tersebut. Parameter yang digunakan adalah porositas dan saturasi air. Untuk perbandingan porositas hasil perhitungan $C T$ dengan data batuan inti (core) ditampilkan pada Gambar 6a, dapat dilihat bahwa pada gambar tersebut memiliki korelasi yang cukup baik. Dengan melakukan regresi plot data porositas $C T$ dan Core, kemudian diperoleh persamaan dengan nilai $R^{2}$ sebesar 0.903 .

Sedangkan untuk korelasi antara porositas log dengan porositas batuan inti (core) ditampilkan pada Gambar $6 \mathbf{b}$. Terlihat bahwa pada kurva tersebut masih banyak data $\log$ yang menjauhi nilai batuan inti, dimana nilai porositas batuan inti sebagai acuan dalam validasi keakuratan hasil perhitungan. Dengan melakukan regresi plot data porositas $\log$ dan Core, diperoleh persamaan dengan nilai $R^{2}$ sebesar 0.627 .

Selanjutnya untuk korelasi antara porositas log dengan porositas $C T$ ditampilkan pada Gambar 6c. Terlihat bahwa pada kurva tersebut masih banyak data porositas $\log$ dan porositas $C T$ yang berjauhan. Dengan melakukan regresi plot data porositas $\log$ dan Core, diperoleh persamaan dengan nilai $R^{2}$ yang lebih kecil dibandingkan dengan 2 kurva sebelumnya yaitu 0.682 .

Berdasarkan 3 kurva perbandingan porositas tersebut (Gambar 6), nilai porositas yang mendekati hasil perhitungan dari laboratorium (data core) adalah porositas $C T$ yang menunjukkan korelasi yang baik dan memiliki nilai $R^{2}$ yang lebih besar dibandingkan persamaan kurva dari porositas core terhadap log dan porositas $\log$ terhadap $C T$. Perbedaan nilai yang jauh ini dapat disebabkan karena pada perhitungan hasil $\log$, nilai yang diambil adalah secara rata-rata hasil perhitungan software. Sedangkan pada batuan inti (core), data diperoleh dari perhitungan setiap sampel batuan. Pada hasil perhitungan $C T$ lebih khusus diperoleh berdasarkan plotting pada zona disetiap 15 titik pada core dengan panjang $1 \mathrm{~m}$. Nilai porositas ini akan mempengaruhi hasil perhitungan permeabilitas, dimana porositas berbanding lurus terhadap permeabilitas. 
Perbandingan permeabilitas prediksi PGS terhadap permeabilitas core ditampilkan pada Gambar 7a. Dapat dilihat pada gambar tersebut, perbandingan antara permeabilitas prediksi dengan permeabilitas core memiliki korelasi yang baik. Semakin dekat data terhadap gradien bernilai satu, maka semakin dekat nilai permeabilitas prediksi terhadap permeabilitas batuan inti. Namun, ada beberapa titik yang menjauhi garis gradien bernilai satu atau menyimpang. Diperoleh nilai $R^{2}$ pada kurva plot regresi log-log data permeabilitas core dengan permeabilitas PGS adalah sebesar 0.906 .

Gambar 7b merupakan kurva perbandingan permeabilitas log terhadap permeabilitas PGS. Dapat dilihat, perbandingan antara permeabilitas log tehadap permeabilitas PGS memiliki korelasi yang cukup baik. Namun, masih banyak data yang menjauhi garis gradien bernilai satu atau menyimpang. Nilai $R^{2}$ yang diperoleh adalah sebesar 0.641.

Selanjutnya, Gambar 7c merupakan kurva perbandingan permeabilitas log terhadap permeabilitas batuan inti (core). Dapat dilihat pada gambar dibawah ini, perbandingan antara permeabilitas log tehadap permeabilitas core memiliki korelasi yang tidak cukup baik. Dimana masih banyak data yang tersebar menjauhi garis gradien bernilai satu. Nilai $R^{2}$ yang diperoleh kecil yaitu sebesar 0.845 .

Berdasarkan 3 kurva perbandingan permeabilitas tersebut (Gambar 7), nilai permeabilitas yang mendekati hasil perhitungan batuan inti adalah permeabilitas PGS ditunjukkan dengan hasil korelasi yang baik yaitu nilai $R^{2}$ yang cukup besar dibandingkan dengan persamaan kurva dari permeabilitas core terhadap $\log$ dan permeabilitas $\log$ terhadap PGS. Gambar 8 dan 9 menunjukkan tampilan akhir hasil perhtungan permeabilitas log dan PGS.

\section{KESIMPULAN DAN SARAN}

Adapun kesimpulan pada penelitian ini, adalah :
1. Nilai permeabilitas Core Sumur AY-7 pada penelitian ini rata-rata yaitu bernilai $0.864 \mathrm{mD}$, dengan nilai minimum sebesar $0.024 \mathrm{mD}$ dan nilai maksimum sebesar $24.161 \mathrm{mD}$. Nilai permeabilitas PGS Sumur AY-7 ratarata yaitu sebesar $0.897 \mathrm{mD}$, dengan nilai minimum sebesar $0.015 \mathrm{mD}$ dan nilai maksimum sebesar $24.148 \mathrm{mD}$. Nilai permeabilitas log Sumur AY-7 pada penelitian ini rata-rata yaitu bernilai $0.594 \mathrm{mD}$, dengan nilai minimum sebesar $0.002 \mathrm{mD}$ dan nilai maksimum sebesar $5.569 \mathrm{mD}$. Hasil perhitungan permeabilitas menunjukkan bahwa permeabilitas tergolong tight (ketat).

2. Berdasarkan hasil perhitungan permeabilitas $\log$ dan PGS, nilai permeabilitas yang mendekati hasil perhitungan dari laboratorium adalah permeabilitas PGS.

Adapun saran dari penelitian ini adalah: Data yang digunakan sebaiknya lebih banyak dan tidak kurang dari 300 data; Diperlukan data SCAL berupa tekanan kapiler yang dapat mewakili semua rock type yang ditentukan untuk validasi rock type yang lebih akurat; Untuk mendapatkan pemodelan reservoir, dibutuhkan data seismik.

\section{UCAPAN TERIMA KASIH}

Penulis mengucapkan terima kasih kepada semua pihak yang telah membantu dengan memberi arahan, diskusi serta dukungan yang bermanfaat selama pengerjaan penelitian ini.

\section{DAFTAR PUSTAKA}

Darman, H. dan Sidi, F. H. 2000. An Outline of The Geology of Indonesia. Makalah Ikatan Ahli Geologi Indonesia (IAGI). Vol 20th. Indonesia. 
Demir, M. dan Demiral, B. 2001. Effect of Pore Size Distribution On Porosity Measurement By Computerized Tomography. Paper Society of Core Analysis. SCA 2001-49.

Dewanto, O., Mulyatno, B.S., Rustadi dan Wibowo, R.C. 2017. Determining the Temperature of Shale Material Conversion Into Crude Oil Based on Organic Clay and Organic Carbonate Test Outside Reservoir. International Journal of Mechanical and Mechatronics Engineering, IJMME. Vol:17 No:05. ISSN: 2077-124X (Online), 2227-2771 (Print). Page: 8489.

Gardner, W.R.,. 1958. Some Steady State Solutions Of The Unsaturated Moisture Flow Equation With Application To Evaporation From A Water Table. Soil Science. 85: 228-232.

Harsono, A.,. 1994. Teknik Evaluasi Log. IATMI. Schlumberger Data Services. Jakarta.

Irawan, D. dan Utama, W.,. 2009. Analisis Data Well Log (Porositas, Saturasi Air, dan Permeabilitas) untuk Menentukan Zona Hidrokarbon, Studi Kasus: Lapangan "ITS" Daerah Cekungan Jawa Barat Utara. Jurnal Fisika dan Aplikasinya vol. 5, No.1. Surabaya: Institut Teknologi Sepuluh November.
Koesoemadinata, R.P.,. 1980. Geologi Minyak dan Gas Bumi. Bandung: Institut Teknologi Bandung. 296 p.

Listiyowati, L.N.,. 2018. Perbandingan Analisis Porositas Porites Menggunakan Teknik Micro-CT dan Optik. Riset Geologi dan Pertambangan, vol. 28, No.1 (91-100). Bandung.

Permadi, P., and Susilo, A. 2009. Permeability Prediction and Characteristics of Pore Structure and Geometry as Inferred from Core Data. Paper Society Petroleum Engineers (SPE) 125350-PP. Abu Dhabi.

Permadi, P. dan Wibowo, A.S.,. 2013. Kozeny's Equation For Better Core Analysis. Paper Society of Core Analysis (SCA) 2013-048. International Symposium of The Society of Core Analysis. Napa Valley, California.

Sinclair, S., Gresko, M., and Sunia, C.,. 1995. Basin Evolution of the Ardjuna Rift System and its Implications for Hydrocarbon Exploration, Offshore Northwest Java, Indonesia. Indonesian Petroleum Association (IPA) Proceedings, $24^{\text {th }}$, hal 147-162. Annual Convention, Jakarta.

Yogi, A. 2018. Estimasi Permeabilitas dengan Beberapa Metode Karakterisasi Reservoar Untuk Formasi Talang Akar. Jurnal Lembaga Publikasi Minyak dan Gas Bumi, Vol. 52 No.1, April 2018 : 35. Jakarta Selatan: PPPTMGB LEMIGAS.

Tabel 1. Klasifikasi Rock Type PGS dan Deskripsi Geologinya

\begin{tabular}{|c|c|c|c|}
\hline PGS & ROCK TYPE & PERSAMAAN & DESKRIPSI GEOLOGI \\
\hline PGS-1 & RT-1 & $\sqrt{\frac{k}{\varnothing}}=0.1169\left(\frac{k}{\emptyset^{3}}\right)^{0.4917}$ & $\begin{array}{c}\text { Didominasi oleh batuan Limestone Shally } \\
\text { with Stylolite, dengan ukuran butir dari } \\
\text { sangat halus sampai kasar. }\end{array}$ \\
\hline PGS-2 & RT-2 & $\sqrt{\frac{k}{\varnothing}}=0.4394\left(\frac{k}{\emptyset^{3}}\right)^{0.2548}$ & $\begin{array}{c}\text { Didominasi oleh batuan Limestone Shally } \\
\text { with Stylolite, dengan ukuran butir dari } \\
\text { sangat halus sampai halus, mengandung } \\
\text { karbonatan. }\end{array}$ \\
\hline
\end{tabular}




\begin{tabular}{|c|c|c|c|}
\hline PGS-3 & RT-3 & $\sqrt{\frac{k}{\emptyset}}=0.344\left(\frac{k}{\emptyset^{3}}\right)^{0.2302}$ & $\begin{array}{c}\text { Didominasi oleh batuan Limestone Shally } \\
\text { with Stylolite, dengan ukuran butir dari } \\
\text { sangat halus sampai halus, mengandung } \\
\text { mineral Kuarsa }\end{array}$ \\
\hline PGS-4 & RT-4 & $\sqrt{\frac{k}{\varnothing}}=0.1899\left(\frac{k}{\emptyset^{3}}\right)^{0.2256}$ & $\begin{array}{c}\text { Didominasi oleh batuan Limestone Shally, } \\
\text { dengan ukuran butir dari sangat halus } \\
\text { sampai halus. }\end{array}$ \\
\hline
\end{tabular}

Tabel 2. Hasil Perhitungan Nilai $A, B$, dan $c$ Untuk Setiap Tipe Batuan

\begin{tabular}{|c|c|c|c|c|c|c|c|c|c|}
\hline $\begin{array}{c}\text { ROCK } \\
\text { TYPE }\end{array}$ & Persamaan & Swirr vs $\boldsymbol{M}$ & $\boldsymbol{M}$ & $\boldsymbol{n}$ & $\boldsymbol{a}$ & $\boldsymbol{b}$ & $\boldsymbol{A}$ & $\boldsymbol{B}$ & $\boldsymbol{c}$ \\
\hline RT-1 & $\sqrt{\frac{k}{\varnothing}}=0.1169\left(\frac{k}{\emptyset^{3}}\right)^{0.4917}$ & Swirr $=0.5936 \mathrm{k}^{-0.145}$ & 0.594 & 0.145 & 0.117 & 0.492 & 1.983 & 7.013 & 2.880 \\
\hline RT-2 & $\sqrt{\frac{k}{\varnothing}}=0.4394\left(\frac{k}{\emptyset^{3}}\right)^{0.2548}$ & Swirr $=0.5936 \mathrm{k}^{-0.145}$ & 0.594 & 0.145 & 0.439 & 0.255 & 1.039 & 13.523 & 1.479 \\
\hline RT-3 & $\sqrt{\frac{k}{\varnothing}}=0.344\left(\frac{k}{\emptyset^{3}}\right)^{0.2302}$ & Swirr $=0.5936 \mathrm{k}^{-0.145}$ & 0.594 & 0.145 & 0.344 & 0.230 & 0.828 & 14.979 & 2.091 \\
\hline RT-4 & $\sqrt{\frac{k}{\varnothing}}=0.1899\left(\frac{k}{\emptyset^{3}}\right)^{0.2256}$ & Swirr $=0.5936 \mathrm{k}^{-0.145}$ & 0.594 & 0.145 & 0.190 & 0.226 & 0.784 & 15.285 & 3.864 \\
\hline
\end{tabular}

Tabel 3. Persamaan Final Prediksi Permeabilitas PGS

\begin{tabular}{|c|c|}
\hline Rock Type & Persamaan Final \\
\hline RT-1 & $k=2.880 \frac{\emptyset^{1.983}}{S w^{7.013}}$ \\
\hline RT-2 & $k=1.479 \frac{\emptyset^{1.039}}{S w^{13.523}}$ \\
\hline RT-3 & $k=2.091 \frac{\emptyset^{0.828}}{S w^{14.979}}$ \\
\hline RT-4 & $k=3.864 \frac{\emptyset^{0.784}}{S w^{15.285}}$ \\
\hline
\end{tabular}


Tabel 4. Hasil Perhitungan Permeabilitas PGS Sumur AY-7

\begin{tabular}{|c|c|c|c|c|c|c|c|c|c|c|c|}
\hline \multicolumn{6}{|c|}{ ZONA 1} & \multicolumn{6}{|c|}{ ZONA 2} \\
\hline Depth & $\begin{array}{c}\text { Perm } \\
\text { PGS }\end{array}$ & $\begin{array}{c}\text { Perm } \\
\text { Core }\end{array}$ & Depth & $\begin{array}{c}\text { Perm } \\
\text { PGS }\end{array}$ & $\begin{array}{l}\text { Perm } \\
\text { Core }\end{array}$ & Depth & $\begin{array}{c}\text { Perm } \\
\text { PGS }\end{array}$ & $\begin{array}{c}\text { Perm } \\
\text { Core }\end{array}$ & Depth & $\begin{array}{c}\text { Perm } \\
\text { PGS }\end{array}$ & $\begin{array}{l}\text { Perm } \\
\text { Core }\end{array}$ \\
\hline$m$ & $m D$ & $m D$ & $m$ & $m D$ & $m D$ & $m$ & $m D$ & $m D$ & $m$ & $m D$ & $m D$ \\
\hline 1779.42 & 0.898 & 0.91 & 1782.4 & 0.072 & 0.039 & 1932.34 & 0.432 & 0.039 & 1934.99 & 0.137 & 0.047 \\
\hline 1779.63 & 0.063 & 0.042 & 1782.6 & 0.212 & 0.196 & 1932.44 & 3.091 & 0.41 & 1935.36 & 0.249 & 0.066 \\
\hline 1779.9 & 0.127 & 0.024 & 1782.9 & 3.038 & 3 & 1932.54 & 1.587 & 0.578 & 1935.59 & 0.94 & 0.528 \\
\hline 1780.1 & 0.154 & 0.062 & 1783.24 & 1.242 & 1.517 & 1932.63 & 24.148 & 24.161 & 1935.94 & 0.135 & 0.051 \\
\hline 1780.4 & 0.058 & 0.054 & 1783.51 & 0.049 & 0.063 & 1932.94 & 0.033 & 0.957 & 1936.26 & 0.126 & 0.129 \\
\hline 1780.63 & 6.082 & 6.069 & 1783.6 & 0.29 & 0.251 & 1933.01 & 0.022 & 2.541 & 1936.51 & 0.102 & 0.097 \\
\hline 1780.87 & 0.226 & 0.284 & 1783.86 & 0.083 & 0.042 & 1933.07 & 0.229 & 0.15 & 1936.64 & 0.768 & 0.133 \\
\hline 1781.3 & 0.461 & 0.497 & 1784.15 & 0.043 & 0.032 & 1933.13 & 1.431 & 0.567 & 1936.82 & 0.106 & 0.138 \\
\hline 1781.4 & 0.03 & 0.031 & 1784.27 & 0.019 & 0.037 & 1933.49 & 0.064 & 0.118 & 1936.92 & 0.27 & 0.515 \\
\hline 1781.66 & 0.021 & 0.039 & 1784.4 & 0.066 & 0.045 & 1933.64 & 0.035 & 0.085 & 1938.01 & 0.152 & 0.202 \\
\hline 1781.9 & 0.026 & 0.041 & 1784.55 & 0.073 & 0.062 & 1933.83 & 0.061 & 0.121 & 1938.12 & 0.122 & 0.199 \\
\hline 1781.95 & 0.086 & 0.07 & 1785.44 & 0.032 & 0.056 & 1934.4 & 0.015 & 0.26 & 1938.38 & 0.098 & 0.206 \\
\hline 1782.1 & 0.042 & 0.03 & & & & 1934.48 & 0.151 & 0.159 & 1938.48 & 0.121 & 0.116 \\
\hline & & & & & & 1934.71 & 0.122 & 0.234 & 1938.59 & 0.035 & 0.17 \\
\hline & & & & & & 1934.77 & 0.152 & 0.184 & & & \\
\hline
\end{tabular}

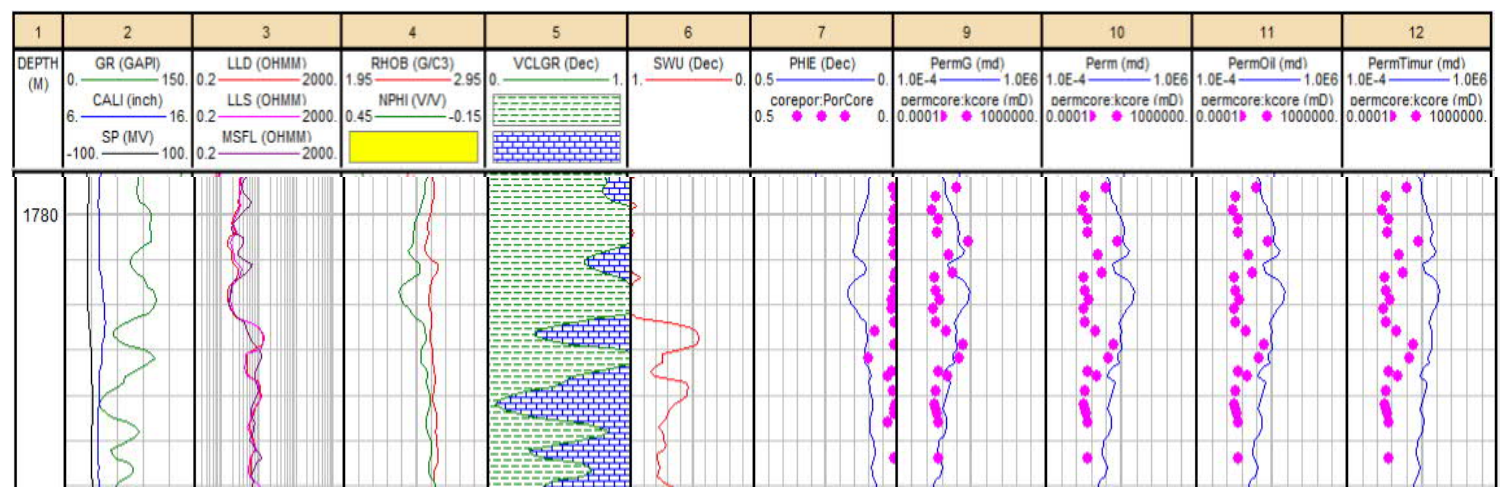

Gambar 1. Hasil Interpretasi Kuantitatif Permeabilitas Zona 1 Sumur AY-7

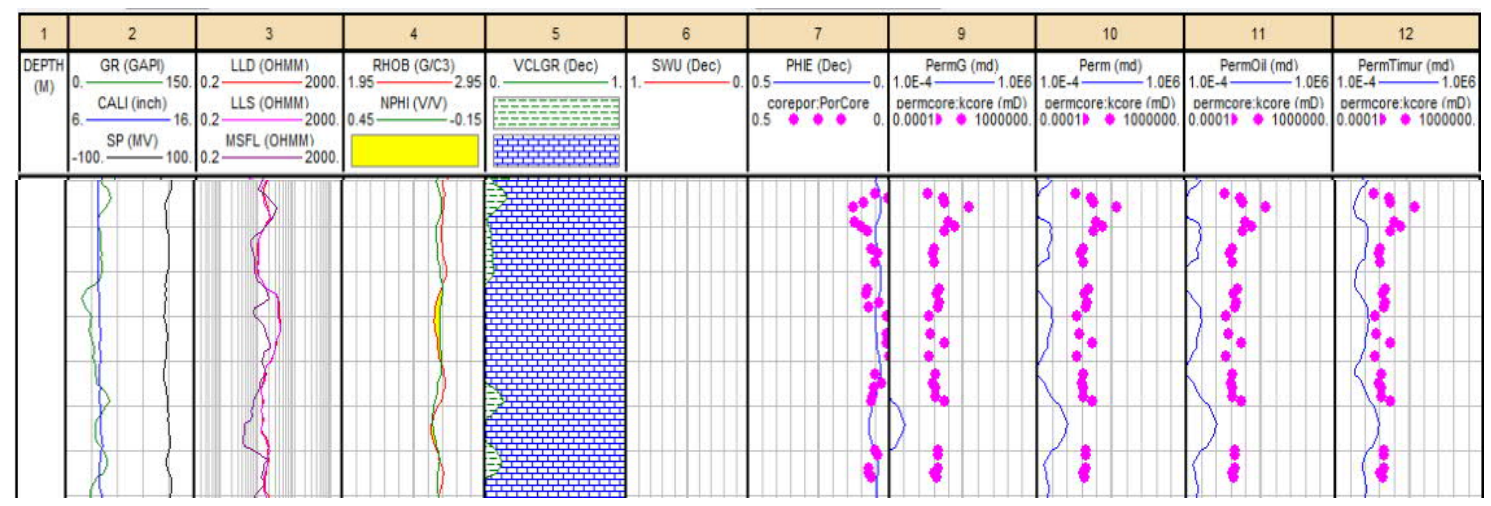

Gambar 2. Hasil Interpretasi Kuantitatif Permeabilitas Zona 1 Sumur AY-7 


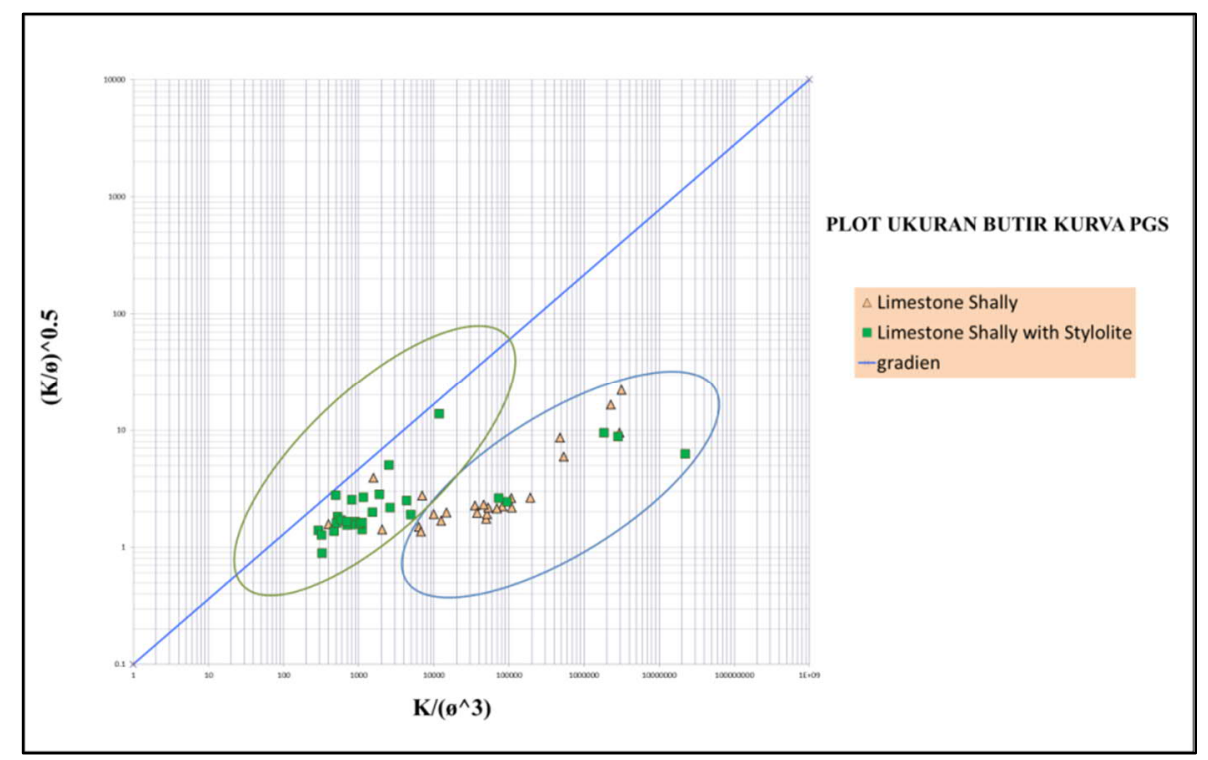

Gambar 3. Plot Ukuran Butir Pada Kurva PGS

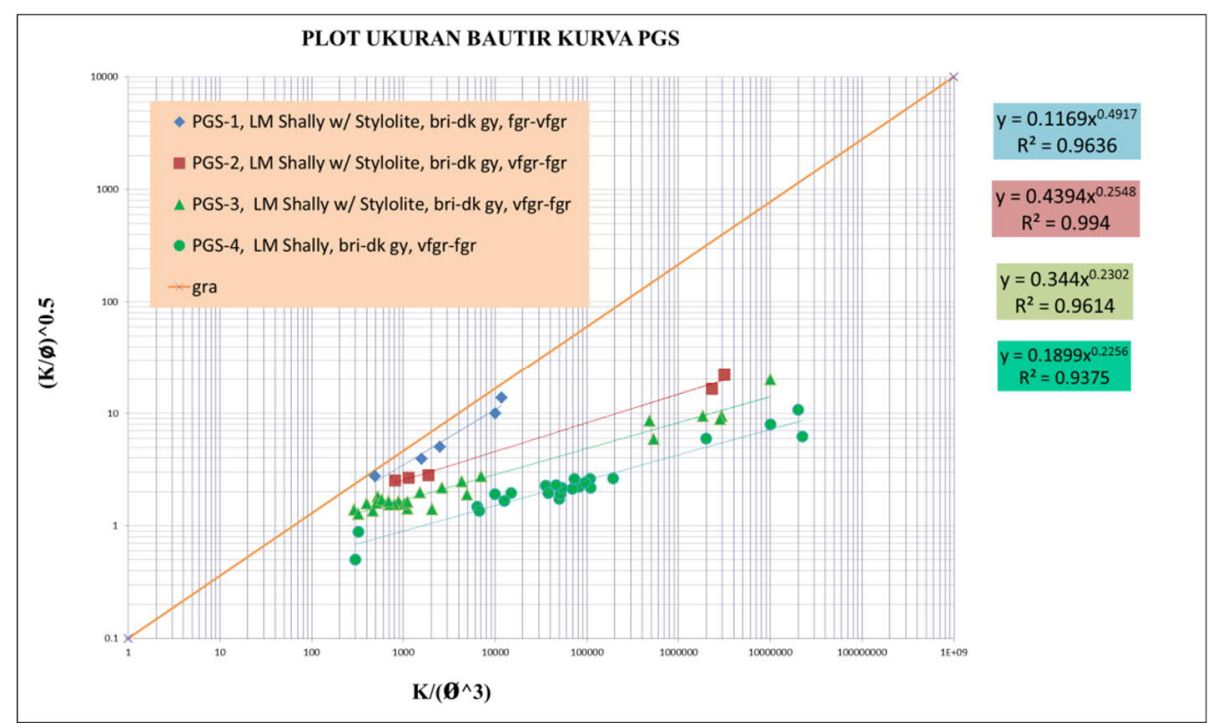

Gambar 4. Final Rock Type dalam Kurva PGS

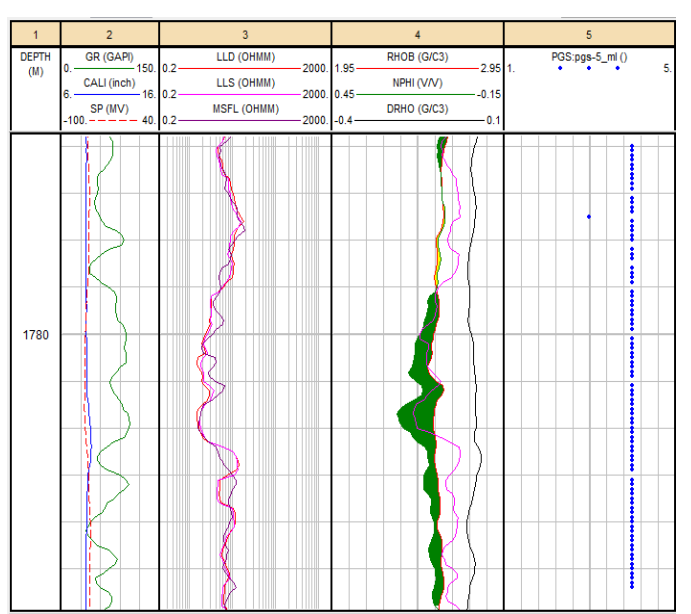

(a)

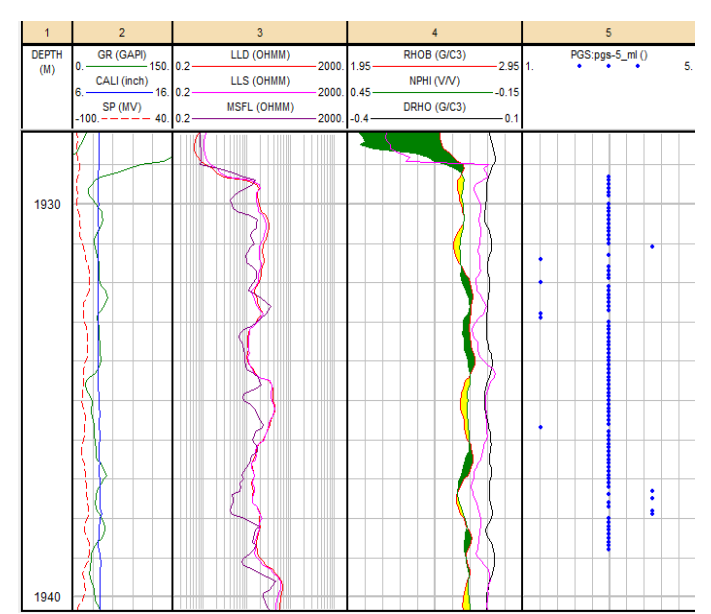

(b)

Gambar 5. Hasil Sebaran PGS Data Sumur AY-7: (a) Pada Zona 1; dan (b) Pada Zona 2 


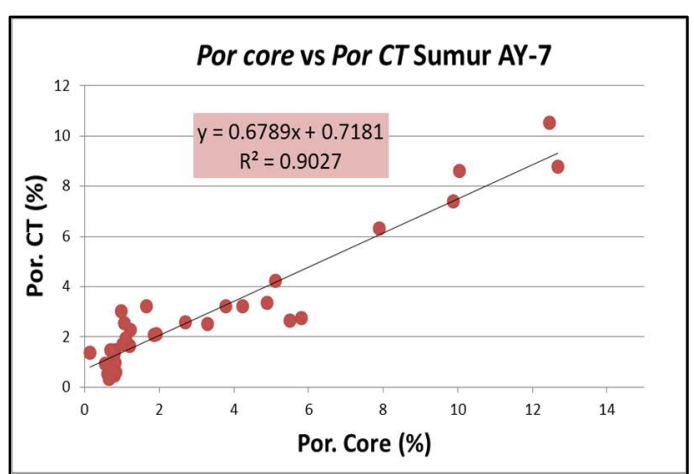

(a)

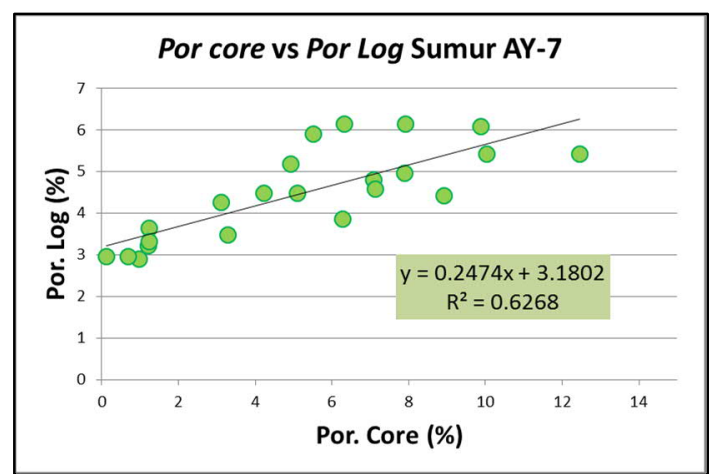

(b)

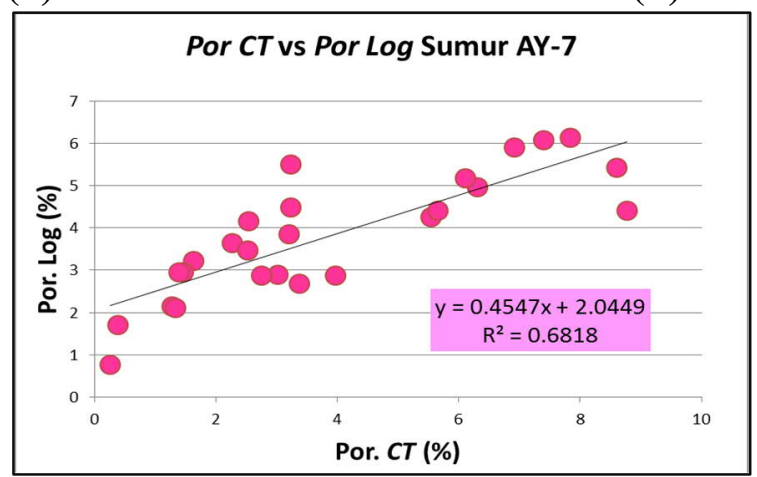

(c)

Gambar 6. Hasil Perbandingan Porositas Pada Sumur AY-7: (a) Porositas CT terhadap Porositas Batuan Inti; (b) Porositas Log terhadap Permeabilitas Batuan Inti; dan (c) Porositas Log terhadap Permeabilitas $C T$

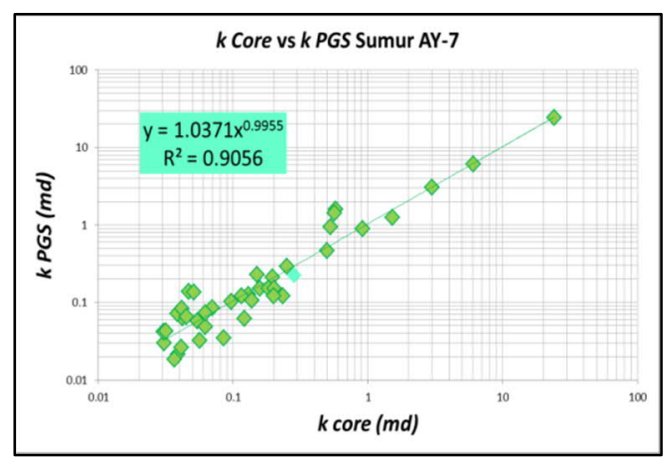

(a)

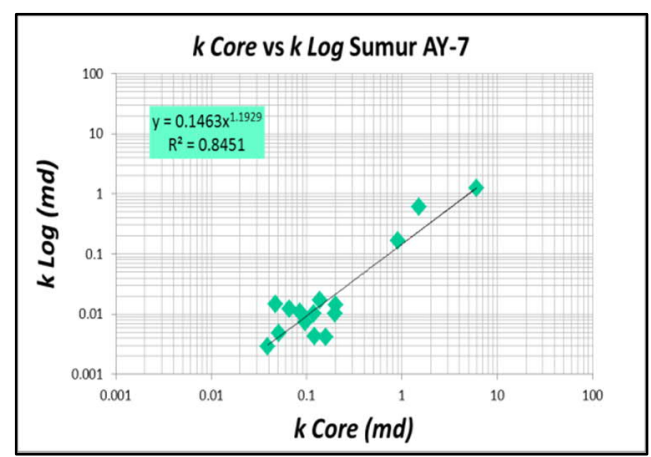

(b)

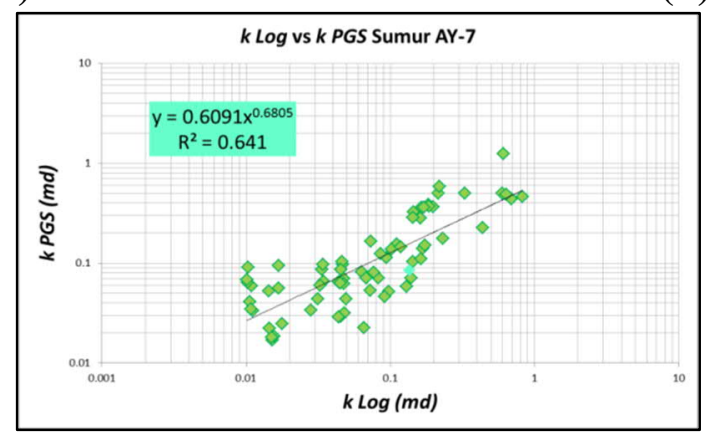

(c)

Gambar 7. Hasil Perbandingan Permeabilitas Pada Sumur AY-7: (a) Permeabilitas PGS terhadap Permeabilitas Batuan Inti; (b) Permeabilitas Log terhadap Permeabilitas Batuan Inti; dan (c) Permeabilitas Log terhadap Permeabilitas PGS 


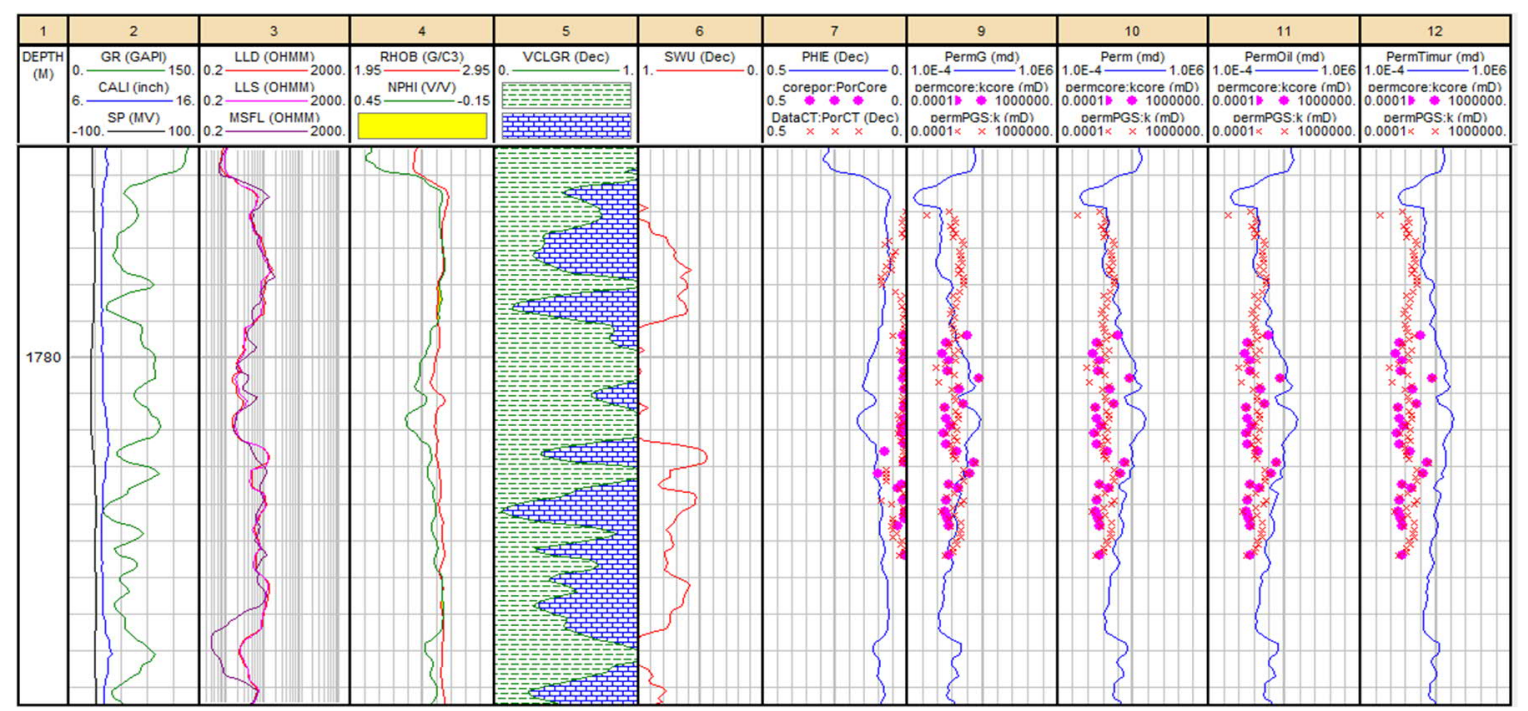

Gambar 8. Perbandingan Porositas CT, Core, dan Log serta Permeabilitas PGS, Core, dan Log Data Zona 1 Sumur AY-7

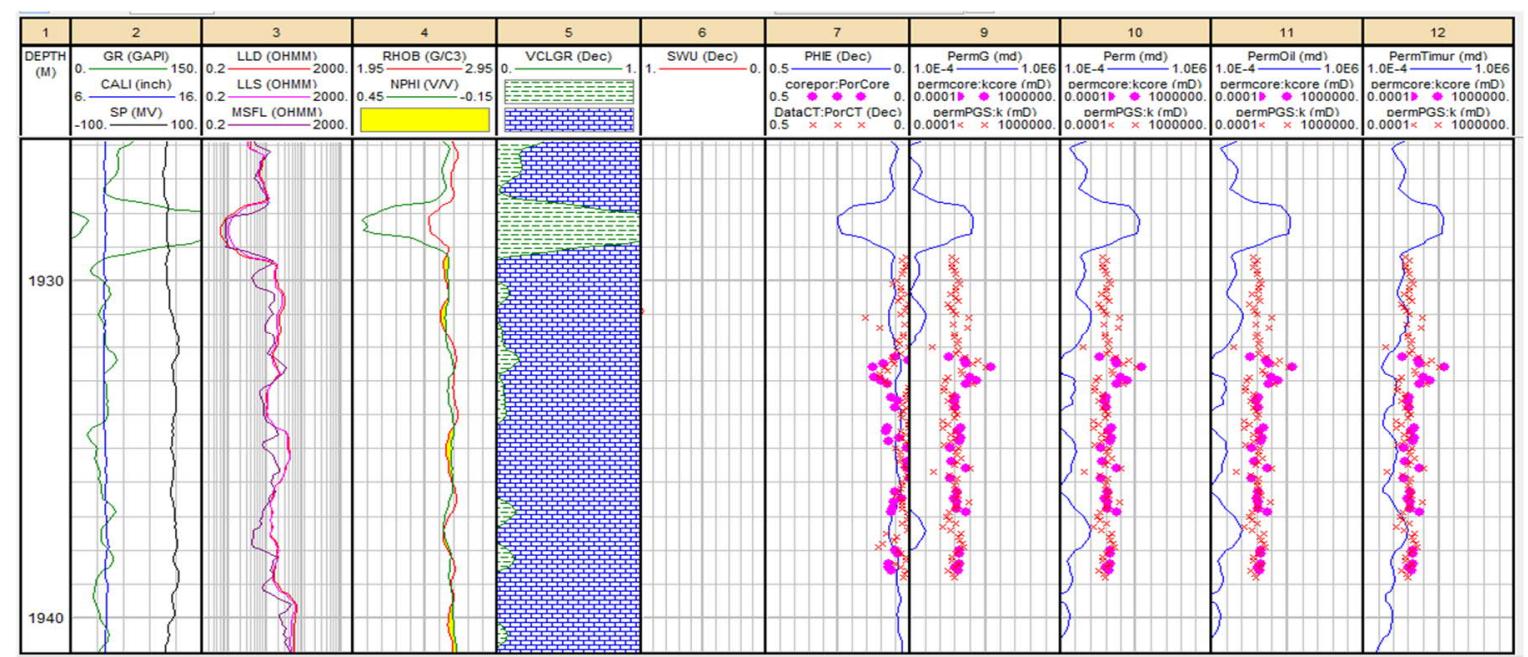

Gambar 9. Perbandingan Porositas CT, Core, dan Log serta Permeabilitas PGS, Core, dan Log Data Zona 2 Sumur AY-7 